\title{
Values of organic producers converting at different times: results of a focus group study in five European countries
}

\author{
Susanne Padel \\ Organic Research Group, \\ Institute of Rural Sciences, \\ Llanbadarn Campus, \\ University of Wales Aberystwyth, \\ AL SY23 3, UK \\ E-mail: sxp@aber.ac.uk
}

\begin{abstract}
This paper presents the results of a focus group study of the values of organic producers entering the sector at different times in Austria, Italy, the Netherlands, the UK and Switzerland. As well as expressing values widely associated with organic farming, such as food quality, health and environmental protection, they also mentioned professional challenge, fairness in the food chain, and maintaining farm income as important. The reviewed literature includes examples of a theory of conventionalisation, which implies that later converting producers are less committed to core organic values than the previously established ones. The conclusions of this paper do not support this idea. In interpreting the observed differences between the values of established and converting producers, it is argued that these are consistent with some aspects of adoption diffusion model, but changes in external circumstances and the learning experience that conversion represents must also be considered.
\end{abstract}

Keywords: conventionalisation; adoption/diffusion; conversion process.

Reference to this paper should be made as follows: Padel, S. (2008) 'Values of organic producers converting at different times: results of a focus group study in five European countries', Int. J. Agricultural Resources, Governance and Ecology, Vol. 7, Nos. 1/2, pp.63-77.

Biographical notes: Susanne Padel is a Research Associate in the Organic Research Group in Institute of Rural Sciences at the University of Wales, Aberystwyth since 1993. She received a PhD in Agricultural Economics from the University of Wales, and worked as a Consultant for organic producers in North Germany after her first degree as Agricultural Engineer from the University of Kassel, Germany. Her current research interest focuses on economic and social issues of organic farming including the development of organic standards.

\section{Introduction}

In 1985, approximately 6000 producers farmed organically in the member countries of the EU 15. By the end of 2004, this had increased to 145,994 producers or $2.3 \%$ of all holdings. In the same period, organic land area grew in the EU-15 from 103,000 ha 
(less than $0.1 \%$ of the total UAA) to 5.39 million ha (4.25\%) (Lampkin, 2005). The market grew from approximately 1 billion ECU at the beginning of the 1990s to approx. 12 to 12.5 billion $€$ in 2004 (Willer and Yussefi, 2005; 2006).

The growth in the organic sector in the EU has been influenced by common regulation for organic farming in the EU introduced in 1991 (EC, 1991), the inclusion of organic farming in the agri-environmental programmes of the common agricultural policy in 1993 (Lampkin et al., 1999), and by the growth in consumer demand for organic food (Michelsen, 2001b). This trend has been accompanied by production on larger scale, and by the growing involvement of multiple retailers and other companies involved in the conventional food market and global trade. There is concern within the organic movement that - irrespective of the causal factors - this growth and development threatens to inhibit the functions of organic agriculture as a more sustainable alternative food system, as an alternative choice for politically motivated consumers, and as a source of inspiration for mainstream agriculture and policy.

This so-called 'conventionalisation' debate in the organic sector has received much attention in the sociological literature about organic farming since Buck et al. (1991). Guthman (2004) reported on the increasing involvement of agri-business creating a lighter version of 'organic' in California through influencing the rule setting, the inter-sectoral dynamics, and the agronomic practices of organic vegetable producers. It is not clear whether this conventionalisation represents a generally perceived phenomenon occurring outside organic farming or a personal conceptualisation of the recent development of organic farming in certain regions or among certain authors.

The main strands of the conventionalisation hypothesis have been summarised by Reed (2005) as follows: organic standards would be lowered with the entry of large-scale businesses, which would appropriate the profits to be made in organic farming and undermine existing organic farmers. 'Conventionalised' organic farming would be conducted in a more intensive, industrialised fashion, diminishing any existing differences between the conventional and organic sectors. Following on from this, it could be deducted that conventionalisation among producers would be reflected in increases in farm size, changes in the use of marketing channels, and less commitment to organic values and principles. In particular, the latter area is the focus of this paper.

In the literature, there is some indication that motives for conversion to organic farming reported in earlier studies differ from those in later ones. This change could indicate a trend towards conventionalisation, but it is equally a trend predicted by the more general model of the adoption and diffusion of innovations (Padel, 2001). However, so far there was only very limited empirical evidence of such changes in basic values or in the motives for conversion. The aim of this paper is to contribute to filling this gap. It reports on focus group discussions about organic values with organic producers, conducted as part of the Organic Revision Project (Padel, 2005). This paper begins with a brief review of the literature relating to values of organic producers and other factors influencing conversion, followed by a description of the research approach. The presentation of results focuses on differences in motives and in the discussion and importance of values between early and later converters, followed by a discussion with reference to the conventionalisation debate and the adoption model. 


\section{Background}

Studies have compared the attitudes of organic with conventional producers with the aim to identify motives for conversion as an explanatory variable of the willingness to convert. The results show many shared attitudes, such as on the financial prospects of farming, as well as some differences, such as in attitudes to the environment and to the future potential of organic farming (Fairweather, 1999; Maurer, 1997; McCann et al., 1997). Darnhofer et al. (2005) identify five clusters of producers, ranging from committed conventional to committed organic, but highlight the heterogeneity in farmers' attitudes, preferences and goals across groups. Other studies similarly suggest considerable variation among both organic and non-organic producers.

There is some indication in the literature that motives for conversion in earlier studies differ from those in later ones (Padel, 2001). Michelsen and Rasmussen (Michelsen, 2001a; Michelsen and Rasmussen, 2003) compare the responses of three very similar large-scale surveys of organic farmers in Denmark, which were conducted at different times, and find a shift from more idealistic to utilitarian motives; a higher proportion of respondents mentioned economics and the environment as important in the later surveys. The later converters also voiced less criticism of conventional agriculture, but saw organic farming as a professional challenge.

Lund et al. (2002) find differences in values between the pioneers of organic farming and later entrants in Norway, based on semi-structured interviews with 11 organic producers. The pioneers expressed a more eco-centric view, emphasising a holistic perspective and interpreting questions in larger frameworks, whereas economic reasons appeared more important for later entrants.

Other studies have attempted to classify organic producers based on their values. Vartdal (1993) classifies organic farmers in Norway as Anthroposophists (influenced by bio-dynamic agriculture and Rudolf Steiner with strong commitment to his ideas); Ecosophists (motivated by green ideas, the environmental and back to the land movement) and Reformists ('normal' farmers with a pragmatic approach to organic agriculture). Vartdal (1993) sees this latter group as similar to the early majority in the adoption model. She also comments on the lower proportion of producers with a farming background in the first two clusters, compared with the third group. Similarly, Darnhofer et al. (2005) identifies clusters of 'pragmatic' and 'committed' organic farmers, in seeking to understand decision-making in relation to organic conversion in Austria.

Differences between earlier and later adopters of an innovation are not a unique feature of the organic sector, but form the basis of the adoption/diffusion model of innovations in agriculture (Rogers, 1983; Rogers and Shoemaker, 1971). According to the adoption model, differences between early and later adopters can be expected not only in attitudes and goals - with later adopters likely to be more profit oriented - but also in farm size and in professional background. The diffusion process of organic agriculture is in many ways similar to a typical diffusion process as described in the model (Padel, 2001). The model has considerable shortcomings, one of them being that a much wider range of farm-specific and external factors are mentioned in the literature as influencing the conversion process (see Table 1). The conversion process to organic farming also appears rather complex, which would limit the applicability of this model. 
Table 1 Factors influencing the decision to convert to organic farming

\begin{tabular}{|c|c|c|}
\hline Personal & Farm-specific & External \\
\hline Personal characteristic & Yield potential and variability & Relative profitability \\
\hline Background & Farm size & Organic support payments \\
\hline Age & Farm type and enterprises & Organic market outlets \\
\hline Social network & Capital resources & Organic premiums \\
\hline Sex & Labour resources & Input and output prices \\
\hline Goals, objectives, values & Risk & Subsidies \\
\hline \multicolumn{3}{|l|}{ Lifestyle and health } \\
\hline Organic farming knowledge & & Institutional factors \\
\hline Technical & & Availability of information \\
\hline Profitability & & Research \\
\hline \multirow[t]{2}{*}{ Market development } & & Advisory support \\
\hline & & Loans \\
\hline Personal attitudes & & Social factors \\
\hline Toward the environment & & $\begin{array}{l}\text { Acceptability in the farming } \\
\text { community }\end{array}$ \\
\hline \multicolumn{3}{|l|}{ Toward inputs and technology } \\
\hline \multicolumn{3}{|l|}{ Toward business } \\
\hline Toward challenge and change & & \\
\hline
\end{tabular}

Source: Padel (2002).

\section{Approach}

The focus group research presented in this paper was conducted as part of the Organic Revision Project. The project aims to assist the EU Commission in the further development of EU regulation 2092/91 in relation to harmonisation of the various organic standards, incorporation of values and principles, and reducing the dependence on non-organic inputs. Focus groups were held in five countries to explore the range of values held and to contrast the results between countries and between earlier and later adopters (the latter not reported here; for further details see Padel, 2005). The research was conducted and reported by a partnership of five national teams, coordinated by the author, who was also responsible for the comparative analysis.

All the countries where focus groups were conducted have a well-established organic sector but differ in relation to the uptake of organic farming (see Table 2). The history of organic agriculture in Austria and Switzerland began with the first bio-dynamic farms in the 1920s. The organic-biological agriculture of Müller and Rusch originated in Switzerland and has significantly influenced the organic movement in Austria, too, where pioneer producers had attended courses held by them. Both countries have experienced significant growth since the early 1990s after organic policy support was introduced, and they are among those with highest uptake in the EU. Italy also has an above-average uptake, but here there is a relatively young organic sector with dramatic growth since the early 1990s and very strong regional differences. The Netherlands has a strong tradition of bio-dynamic farming alongside ecological (used as synonym for 
organic agriculture in NL), but growth has been moderate compared to other countries and uptake is below EU average. The UK also has strong and long tradition of organic farming, which goes back to Lady Eve Balfour and Sir Albert Howard in the late 1940s. After many years of trailing behind other European countries, the UK experienced an increase in the number of organic farms and land area, but growth has slowed again in recent years. In UK land area and the number of farms are similar to the EU average, but the UK has one of the largest retail markets for organic food in Europe.

Table 2 Organic sector in the countries studies in 2004

\begin{tabular}{lcccccc}
\hline & Holdings & $\begin{array}{l}\text { \% of } \\
\text { holdings }\end{array}$ & Area & \%UAA & $\begin{array}{l}\text { Retail sales } \\
\text { value }(€)\end{array}$ & $\begin{array}{l}\text { Per capita } \\
\text { expenditure }\end{array}$ \\
\hline Austria & 19,826 & 11.41 & 344916 & 10.6 & $280 \mathrm{~m}$ & 35 \\
Switzerland & 6420 & 8.03 & 112000 & 10.3 & $778 \mathrm{~m}$ & 105 \\
Italy & 36,639 & 1.87 & 954361 & 7.3 & $2.4 \mathrm{~b}$ & 42 \\
UK & 4010 & 1.43 & 690269 & 4.1 & $1.774 \mathrm{~b}$ & 30 \\
Netherlands & 1469 & 1.72 & 48155 & 2.4 & $419 \mathrm{~m}$ & 26 \\
EU-15 (av.) & & 1.58 & & 4.25 & & $\mathrm{n} / \mathrm{a}$ \\
\hline
\end{tabular}

Source: Willer and Yussefi (2006).

There are various models of how values influence behaviour, which lead to a range of research methods, such as attitude surveys, laddering interviews, and focus groups. Values are often unconscious, people are not necessarily happy to talk about them, they are influenced by social factors and are rather difficult to study. Linguistic variations in the meanings of terms can further limit the value of the results. The laddering technique uses one-to-one interviews to study the underlying values of consumer, with questions attempting a deep probing of respondents' cognitive structures (Gutman, 1982; Zanoli, 2004), but this may lead to defensive replies. Quantitative surveys risk being answered at a very superficial level, pressing the responses into false categorisations.

The main advantage of the qualitative social science method of focus groups is that the relaxed atmosphere allows participants to express things that they might withhold in other situations (Anon, 1999). The moderating team can gain further insights beyond the spoken word through observing the interaction between participants. A considerable number of participants can be reached in a relatively shorter time and in a cost effective way. Focus groups are used in commercial market research and academic research. A focus group consists of a prepared discussion of 90-120 min with 6-15 participants focusing on a particular topic (Anon, 1999). The main aim of the focus group discussions in this study was to explore the range of values held by organic producers.

A common discussion guide was used for all the focus groups in this study. This was designed to reveal the range of values among organic producers (and other stakeholders) and to establish which values were most important to the participants. The development of the discussion guide was collaborative and involved one meeting of all the moderators, held to reach a common understanding of the aims of each section; this was followed by a pretest in each country. After the participants' initial introductions, the first section of the discussion guide explored unprompted associations with the topic. The second section approached personal values with a question about the 
participants' personal reasons for involvement with organic farming and the conversion of their farm. This was followed by a more abstract discussion of values and their importance for the organic movement, potential value-conflicts and the prospective values of organic farming in the future. The results presented in this paper based mainly on the second and third section of the discussion guide and groups involving producers.

The teams used contacts within the organic sector to identify suitable regions and potential participants, ensuring that a variety of different climatic conditions were chosen. Producers were part of groups with well-established producers if they have converted before financial support for conversion was first introduced in their country, if not they participated in groups with more recently converted producers. The cut-off point was 1989 in Switzerland; 1991 in Austria and 1994 in Italy, the Netherlands and in the UK (Lampkin et al., 1999). A short recruitment questionnaire was used for the screening of participants invited to each meeting. There was a target number of between 6 and 12 participants in each group (with some need for flexibility), and the aim was to recruit mainly full-time producers (based on self-classification) from a range of farm-types typical for the specific region.

Sixteen focus groups involving a total of 119 producers were conducted in five countries between August and December 2004 (see Table 3). The Austrian focus groups were held in a grassland region, a mixed grassland/arable region, and a mainly arable region. In Italy, groups were held near Rome and in Tuscany, and were attended by cattle and pig farmers, vegetable, fruit and olive producers. The groups in the Netherlands were also largely farm-type specific, including two groups of dairy farmers (one of them bio-dynamic) and one group of arable producers, but it was not possible to recruit a group with recently converted producers. The Swiss groups were held in a lowland and upland region, and included producers with livestock, arable crops and horticultural crops. In the UK, groups were held in England and Wales, and consisted of a mixture of arable, livestock and horticultural producers in both these locations.

Each group discussion lasted for approximately two hours, and a debriefing between the moderator and the observer directly after the meeting formed the basis for a short summary report and first interpretation of the data. For further analysis, the tape recordings were fully transcribed, and the material was coded using a common codebook to facilitate comparative analysis. The codes represented values mentioned in the literature and in the initial summaries, but new codes could be added if necessary. Statements relating to each code were retrieved, summarised and translated to explore differences in the meanings and importance of values.

Despite a common discussion guide and code book, there were some differences in procedures, which have limited the comparative analysis. In the groups in Austria, Switzerland and in the UK, the participants indicated the importance of the values noted down during the discussion by a voting process. In the Netherlands, their values were clustered into theme groups by the participants. In Italy importance of values was assessed during analysis by the extent of coverage of each topic recorded during the discussions. The groups were held in the national language, and the data were then translated into English for the comparative analysis. It is, therefore, difficult to draw firm conclusions about the comparative importance of certain values. For example, differences among related terms (e.g. environmental protection, sustainability and ecology) may have been due to variations in the meanings either as intended by the participants or as understood by the moderators, or they arose during the translation of 
the material. Nevertheless, the results give a good indication of the reasons for personal involvement, the range of values held by organic farmers in several European countries and a number of influencing factors.

Table 3 Place and participants of producers focus groups in all countries

\begin{tabular}{|c|c|c|c|}
\hline Group & Date & Farm type & No of participants \\
\hline 10 groups & \multicolumn{2}{|c|}{ Established organic producers } & 74 \\
\hline AT 2 & 15-Nov-04 & Mixed livestock & 8 \\
\hline AT 3 & 17-Nov-04 & Mixed & 9 \\
\hline IT 2 & 02-Nov-05 & Various & 6 \\
\hline NL 2 & 22-Nov-04 & Bio-dynamic dairy & 3 \\
\hline NL 3 & 22-Nov-04 & Organic dairy & 6 \\
\hline NL 4 & 15-Dec-05 & Predominantly arable & 3 \\
\hline $\mathrm{CH} 2$ & 29-Nov-04 & Predominantly mixed farms & 6 \\
\hline $\mathrm{CH} 5$ & 21-Jan-05 & $\begin{array}{l}\text { Mixed livestock, mountain } \\
\text { region }\end{array}$ & 8 \\
\hline UK 1 & 18-Nov-05 & Various & 15 \\
\hline UK 3 & 08-Dec-05 & Various & 10 \\
\hline 6 groups & \multicolumn{2}{|c|}{ Recently converted (after subsidies) } & 45 \\
\hline AT 4 & 03-Oct-04 & Predominantly cropping & 6 \\
\hline IT 3 & 25-Nov-05 & Various & 9 \\
\hline $\mathrm{CH} 1$ & 23-Nov-04 & Predominantly mixed farms & 6 \\
\hline $\mathrm{CH} 3$ & 29-Nov-04 & Predominantly mixed farms & 6 \\
\hline $\mathrm{CH} 4$ & 21-Jan-05 & $\begin{array}{l}\text { Mixed livestock, mountain } \\
\text { region }\end{array}$ & 10 \\
\hline UK 4 & 10-Dec-05 & Various & 8 \\
\hline 16 groups & & & 119 \\
\hline
\end{tabular}

Source: Padel (2005).

\section{Results}

\subsection{Personal involvement of producers with the organic sector and motives for conversion}

Producers' motives for becoming involved in organic farming covered a broad range; those frequently mentioned in each country are shown in Table 4. Many related terms had initially been mentioned by the producers as their first associations with the term organic and occurred again in the later discussion of values. All participating producers appeared very committed to organic methods, seeing them as the best agricultural practice, as a good example, or as a sustainable alternative to modern agriculture. Some mentioned their personal background or saw a change in personal circumstances as a trigger, for example, their personal health or passing on the farm to the next generation. 
Table 4 Motives for conversion to organic farming of organic producers

\begin{tabular}{ll}
\hline Austria & Ecological and environmental \\
& Freedom from GMO, \\
& Food quality and health. \\
& Concern for the environment and for \\
Italy & sustainability, \\
& Product quality, \\
& Not having to work with chemicals. \\
& Sustainability, \\
& Lifestyle and working environment, working \\
Netherlands & with nature, \\
& Self-sufficiency, \\
& Personal freedom, \\
& Social issues. \\
& Sustainability, \\
& Health of the systems, \\
& Social justice for all partners including fair \\
& returns for producers. \\
Switzerland & Concerns with the direction of conventional \\
& agriculture, \\
& Personal health, \\
UK & Passing on the farm to the next generation, \\
& Personal challenge. \\
\hline
\end{tabular}

Source: own data.

One of the aims of the study was to contrast the motives for farm conversion of the established organic producers with those of the converting organic producers. In Switzerland, early converters' motives appeared influenced by the personality of individual pioneer farmers. The magnitude of the required changes in farming practice during conversion, which varies with farm type, was mentioned as an important factor by both mountain farmers in Switzerland and the group of converting producers in the UK. In Italy, the proportion of new entrants into farming was higher among the newly converted producers, but the sample size is too small to draw any conclusions from this.

Established organic producers in the Netherlands and in Austria were concerned that newly converted farmers did not share their motives and values but instead were converting mainly for economic reasons, such as the conversion grant, direct payments or premium prices and that the popular image of organic farming could suffer as a result: "Nowadays new converters have no feeling or patience for development of their system... They are using increasing amount of inputs and once you start with this, there seems to be no way back" (NL, established).

The focus group of newly converted farmers in the UK was asked to respond to a similar statement that 'later converters are only in it for the money'. All participants in this group disagreed vehemently with such a categorisation. However, they acknowledged the importance of Grant aid in reducing the financial risk of conversion and pointed out that they had to farm for profit, not as a hobby.

No other differences between established and converting organic producers in relation to financial motives were observed. All four groups in Austria, three of which consisted of established organic farmers, attached importance to economic survival as independent farmers and hoped to get a fair price. In the UK and Switzerland, economic 
motives were also mentioned by both the experienced and converting organic producers. In Switzerland, financial motives were mentioned mainly in the mountain areas, where organic farming was seen as a strategy to earn a living and to survive as a farmer. This association of economic motives with a particular geographical region indicates that external conditions may be a more important factor for their importance than the length of time since conversion.

\subsection{Meaning and importance of organic farming values}

All participants, including the recently converted producers, were very engaged in the subsequent discussions about the meanings and the importance of values to the participants and to the organic movement. Table 5 illustrates the range and the level of importance of values held by organic producers in various regions of Europe. The values of food quality, environmental protection, limiting resource use and health were discussed as important in all countries. Sustainability, closed production cycles and independence were held as important values in four countries, but not in Italy.

The teams also reported which themes were frequently discussed in their country. The central topics in Austria included aversion to agro-chemicals, closed cycles, health and environmental protection; however, these organic farmers did not appear to see themselves as environmentalists. They saw agriculture as increasingly marginalised; farm income, profitability and alternatives in marketing were discussed extensively. Among Italian producers, the discussions about food quality and health referred to authenticity of a product, freshness and taste. These participants saw a strong link between organic farming and environmental conservation, which they wanted to communicate to consumers. Systems thinking, health and ecosystem health were not widely discussed. In contrast, the inter-connections within the system were an important focus in the Netherlands. The Dutch team used the words of one participant to summarise this:

\footnotetext{
"Organic agriculture is about producing endlessly [long-term sustainable], with care and respect for humans, animals, plants and soil. Organic farmers produce healthy and tasty food without harming the environment or the development of others. Their farms and agriculture in general are interconnected with small and big world problems" (NL, established).
}

As in Austria, the Swiss team mentioned the producers' concerns for the future of the sector and on fair trading conditions as core issues. In a number of discussions, a concept of the 'health of the ecosystem' emerged as a fundamental value. Also in the UK, the discussions about health and product quality referred to the cycle of health, including soil and animal health in production systems, and personal and consumer health. In all three groups, the need to reduce the use of non-renewable energy was discussed.

In most groups, the attitude to the organic sector was generally positive. Many participants showed a strong professional identity as organic farmers; the professional challenge of organic farming had also been widely represented among the unprompted first associations with the word 'organic' in all five countries. They valued their independence, were proud of their specialist skills, and were pleased to be working in close connection with nature: "Regaining a sense of independence despite being highly regulated by standards" (UK, established).

They derived a high level of job satisfaction from farming organically, associated with a sense of responsibility for the quality of their product and for taking care of the environment. Many felt that organic farming gave them greater opportunity for personal 
development. Although some negative comments were made about regulations, the majority of participants did not seem to experience the organic standards and rules as restrictions on their independence. However, there was strong concern that economic pressure on agriculture in general as well as on the organic sector might cause intensification or increase the size of organic systems, which led to discussions about social aspects of food production.

Table 5 Comparison of important values ${ }^{(a)}$ in all countries

\begin{tabular}{|c|c|c|c|c|c|}
\hline & $A T$ & $\mathrm{CH}$ & $U K$ & $I T$ & $N L^{b}$ \\
\hline Food quality & 1 & $\mathrm{X}$ & 3 & $\mathrm{X}$ & $\mathrm{X}$ \\
\hline Environmental protection & 3 & $\mathrm{X}$ & 3 & $\mathrm{X}$ & $\mathrm{X}$ \\
\hline Limiting resource use & $\mathrm{X}$ & $\mathrm{X}$ & $\mathrm{X}$ & $\mathrm{X}$ & $\mathrm{X}$ \\
\hline Health & 1 & 2 & 1 & $\mathrm{X}$ & $\mathrm{X}$ \\
\hline Sustainability & $\mathrm{X}$ & $1^{\mathrm{c}}$ & 2 & & $\mathrm{X}$ \\
\hline Independence & 2 & $\mathrm{X}$ & $\mathrm{X}$ & & $\mathrm{X}$ \\
\hline Closed production cycles & $\mathrm{X}$ & $X$ & $\mathrm{X}$ & & $\mathrm{X}$ \\
\hline Respect for/farming with nature & $\mathrm{X}$ & 3 & & & $\mathrm{X}$ \\
\hline Alternative model/Education & $X^{d}$ & & $\mathrm{X}^{\mathrm{d}}$ & $\mathrm{X}$ & \\
\hline Professional challenge, $\sim$ pride & & & $\mathrm{X}$ & $X^{d}$ & $\mathrm{X}$ \\
\hline Fairness in the food chain & $\mathrm{X}$ & $\mathrm{X}$ & & & $\mathrm{X}$ \\
\hline Systems approach & & $X$ & $\mathrm{X}$ & & $\mathrm{X}$ \\
\hline Regional production & $\mathrm{X}$ & & $\mathrm{X}$ & & $\mathrm{X}$ \\
\hline Animal welfare & & $X^{\mathrm{d}}$ & $X^{\mathrm{d}}$ & $X^{d}$ & $\mathrm{X}$ \\
\hline Global fairness & $\mathrm{X}$ & & & & $\mathrm{X}$ \\
\hline Social networks/well-being & $\mathrm{X}$ & $X^{\mathrm{d}}$ & $\mathrm{X}$ & & \\
\hline Avoiding residues/non-polluting & & $\mathrm{X}$ & $\mathrm{X}$ & & \\
\hline Farm diversity & $\mathrm{X}$ & & $X$ & & \\
\hline Family farm/Future generation & $X^{d}$ & $3^{d}$ & & & \\
\hline Quality of live on the farm & $\mathrm{X}$ & & & & \\
\hline Trust & & & $X$ & & \\
\hline Low food miles & & & $\mathrm{X}$ & & \\
\hline Authenticity/freshness and taste & & & $X^{\mathrm{d}}$ & $X^{d}$ & \\
\hline Integrity & & & $\mathrm{X}$ & & \\
\hline Rural employment & & $X^{\mathrm{d}}$ & & & \\
\hline
\end{tabular}

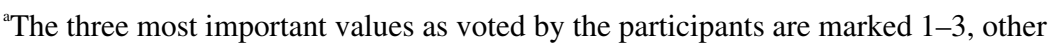
values of importance are marked by X.

${ }^{b}$ In NL participants sorted values in clusters but did not vote on importance.

'The value the term was ecological sustainability.

${ }^{\mathrm{d}}$ Values found more important in groups with converting producers.

Source: Own data. 
In the discussion of values, only very few differences were observed between established and recently converted producers. Recently converted producers in UK and Austria discussed the role of organic farming as an alternative model for agriculture and food production in greater detail than established producers. The same was true for animal welfare in the UK and in Switzerland, and for the family farm and rural employment in Switzerland. Converting producers in Italy and the UK attached importance to producing fresh food of superior taste. Only the value of closed production cycles appeared more important to established organic producers than other participants; however, closely related values of environmental protection and minimising pollution were also discussed in groups with recent converters.

Specific values were important to participants coming from particular farm types. Values related to animal husbandry were important mainly to livestock producers. In the Netherlands, only the group of established bio-dynamic farmers discussed animal welfare extensively, whereas closing nutrient cycles was discussed as a real challenge by the group of arable producers, reflecting the context of increasing specialisation in Dutch agriculture. Other Dutch groups also discussed the need for extended co-operation between arable and animal producers as an important means to close these cycles. In Switzerland, the need for farm survival was discussed in greater detail in the mountain area than in the lowland regions.

In a second part of this section of the discussion guide, participants were asked to express what values of organic farming they considered likely to become more important in the future. This question was intended to approach the importance of values through the use of projective techniques. Most values that were expected to be important in organic farming in the future had already been discussed beforehand, but the subject areas of limiting the use of energy from non-renewable resources; environmental conservation; building trust through closer links and communication throughout the whole organic food chain and limiting contamination with Genetically Modified Organisms (GMOs) were mentioned here. The discussions illustrated producers' awareness of general trends as well as concerns that an improved standard of general agriculture, for example, in relation to animal welfare, might reduce demand for organic products.

\section{Discussion}

The analysis showed much common ground and only very few differences between established and converting producers' motives and discussed values. Motives for becoming involved in organic farming were wide ranging but similar to those identified in the literature. The focus groups did not reveal substantial differences between the motives of earlier and later converters, except that converting producers acknowledged the role of Grant aid in reducing financial risks. In the discussions of values the groups of converting producers appeared more concerned about the need for organic farming to keep pace with general developments in agriculture, for example, in relation to environmental conservation and animal welfare, and to meet consumer expectations. They emphasised more strongly the roles of organic farming as an alternative form of agriculture and in agricultural and general education, whereas for established producers, closed production cycles and systems values such as systems health appeared especially important. 
The results also provide some interesting insights into the importance of certain factors influencing conversions to organic farming. Mountain farmers in Switzerland and some converting producers in the UK pointed out that they found conversion easy because their systems were very similar to organic beforehand, indicating that the magnitude of the required changes might account for some differences in attitudes. Values related to animal welfare were more widely discussed by livestock farmers, whereas improved soil fertility was important to arable producers. This confirms the importance of farm-specific factors, such as farm type and enterprise structure and intensity of production before conversion.

The evidence in the literature that relates to a shift in organic values in support of the conventionalisation hypothesis is inconsistent. Michelsen and Rasmussen (Michelsen, 2001a; Michelsen and Rasmussen, 2003) find that there was a higher prevalence of utilitarian motives among later converters, but despite the observed differences, they highlight that both groups strongly identified with organic values. In contrast, Lund et al. (2002) see later entrants as having a more superficial relationship to organic principles. In two Italian studies, a category of so called 'eco-sly' producers is described as being interested only in subsidies but not in values, but also as non-professional in their farming activities (Scaridigno, 2001; Pugliese, 2001).

Also in this study, established organic producers in the Netherlands and in Austria expressed concerns about the dominance of economic motives and about a loss of core values among new entrants in a very similar way to examples from the literature, but the results of all the focus groups show no differences to support these concerns. Financial motives for conversion and economic values of farm survival were mentioned by many participants in several countries in groups of both experienced and converting producers and the converting producers strongly disagreed with being labelled like that.

Professional challenge as a motive and other values related to professional identity were mentioned in most groups in this study, and not only in groups with recently converted producers as in the Danish surveys by Michelsen and Rasmussen. All participants in these focus groups were full-time producers (based on self-classification), whereas in later Danish survey, the proportion of full-time producers was higher than in earlier studies. Unsurprisingly, the importance of professional values to organic producers appears to be related to the proportion of time spent farming, making professional background and the level of involvement important factors to consider in any analysis.

There are also indications that external circumstances influence how strongly economic issues matter to organic farmers. In Switzerland, economic motives were mentioned both by established and converting producers especially in the mountain regions, where economic survival is likely to be more difficult than in the lowland regions. However, in many groups, concerns for the economic future of organic farming and of farming in general were discussed at length, and the producers were clearly worried about being able to survive if the current declining trend of agricultural prices continues. A worsening economic situation in agriculture could, therefore, provide an alternative explanation for the more frequently observed mentioning of financial motives that was observed in Denmark, rather than conventionalisation and lack of commitment to organic values among new entrants.

The adoption-diffusion model indicates that trends leading to differences in goals and farm sizes are a typical feature of the diffusion process, and therefore, classifies innovators and early and later adopters on the basis of personal, farm specific and social 
characteristics. In line with this model, the differences in values and goals as observed in some studies should be expected when organic farming is more widely adopted (Padel, 2001). The model initially led to predictions of higher profit orientation among the earlier adopters, but modifications particularly in the area of farming goals were suggested to accommodate environmental innovations (e.g. by Taylor and Miller, 1978). However, this study shows that other external factors appear also important that are not considered in the adoption-diffusion model, in particular the external economic circumstances. The adoption diffusion model, therefore, does not provide a completely satisfactory alternative theoretical model.

In Austria and Switzerland, particularly the established organic producers mentioned that they had been influenced by organic pioneers in their conversion. In the discussion, these participants referred more frequently to concepts associated with organic core values, such as closed production cycles, systems thinking, a cycle of health from healthy soils to healthy people and agro-ecosystem health. It is likely that the few farmers who converted in the early days had intensive contact with pioneers and thus more direct exposure to theories and core values than new entrants at a time of mass-conversion. The established farmers in the Netherland provided another explanation in reporting that the experience of working with natural cycles on their own farms had taught them to become more organic over time. Similarly, UK and Italian producers referred to the need for learning or relearning, that is, to forget some of what they had learnt previously about agriculture and to learn to solve problems in a more systems-oriented way. This would indicate that observed value differences between pioneers and later converters (e.g. Lund et al., 2002) could be a result of the longer-term involvement with organic issues and greater learning experience of those who converted earlier, rather than reflecting differences in attitudes at the beginning of conversion. Conversion should be seen as a personal learning process drawing on experiences from within the farm and contacts outside and not only a change of the farming system.

\section{Conclusion}

The results of this focus group study show that professional background, farm type and external economic circumstances are likely to influence organic producer motives and values. According to the adoption/diffusion model some change in personal and farm-specific characteristics between earlier and later adopters are to be expected. It is important that in exploring some differences in values as evidence for conventionalisation the mistake is not repeated, for which the adoption/diffusion model was widely criticised at the time (e.g. by Taylor and Miller, 1978): seeking the explanations mainly in the one area such as personal characteristics of an individual producer but ignoring other factors that might be equally important.

Farmers who converted early to organic farming have been exposed to organic ideas and experiences for a much longer time and probably in greater intensity than those who have converted more recently; they have learnt to become 'more organic' over time and to identify more strongly with organic values. Because of this learning process during and after conversion, it appears difficult to establish differences in attitudes and values between farmers empirically unless the farmers have been surveyed at a point of similar period of exposure to organic methods and ideas. 
The challenge to the organic food and farming sector, particularly in periods of rapid growth, is to ensure that all new entrants have the same opportunity to learn about the basic values and principles as the early pioneers had. Rather than placing new entrants in a box marked 'conventionalised organic producers', the organic movement and established organic producers need to actively engage with these new entrants so that they learn about wider organic principles over time and become committed supporters.

\section{Acknowledgement}

Funding from the EU Commission for the Organic Revision Project (Contract No. FP6-502397) is gratefully acknowledged (www.organic-revision.org). The views expressed are those of the author, not of the commission. I would also like to thank all participants in the focus groups discussions, and Hugo Alroe, Ton Baars, Antonella Bodini, Elisabeth Fromm, Rahel Kilchsperger, Jos Langhout, Gerhard Plakholm, Raffaella Roviglioni, Otto Schmid, Henk Verhoog and all others involved in developing the procedure, running the groups and analysing the results in each country, the reviewers for their constructive comments and Steve Lowman for copy-editing.

\section{References}

ANON (1999) Getting to the Right Psychological Level in Your Focus Group, Orangeburg NY: Market Navigation.

Buck, D., Getz, C. and Guthman, J. (1991) 'From farm to table: the organic vegetable commodity chain of Northern California', Sociologica Ruralis, Vol. 37, pp.3-20.

Darnhofer, I., Schneeberger, W. and Freyer, B. (2005) 'Converting or not converting to organic farming in Austria: farmer types and their rationale', Agriculture and Human Values, Vol. 22, pp.39-52.

EC (1991) 'Council Regulation (EEC) No 2092/91 of 24 June 1991 on organic production of agricultural products and indications referring thereto on agricultural products and foodstuffs', Official Journal of the European Communities, Vol. L198, pp.1-15.

Fairweather, J.R. (1999) 'Understanding how farmers choose between organic and conventional production: results from New Zealand and policy implications', Agriculture and Human Values, Vol. 16, pp.51-63.

Guthman, J. (2004) 'The trouble with 'Organic Lite' in California: a rejoinder to the 'conventionalisation' debate', Sociologia Ruralis, Vol. 44, pp.301-316.

Gutman, J. (1982) 'A means-end chain model based on consumer categorization processes', Journal of Marketing, Vol. 4, No. 6, pp.60-72.

Lampkin, N. (2005) Eurodata for Organic Farming, Aberystwyth, Organic Centre Wales, Institute of Rural Sciences, University of Wales.

Lampkin, N.H., Foster, C., Padel, S. and Midmore, P. (1999) The policy and regulatory environment for organic farming in Europe, Hohenheim: University of Hohenheim.

Lund, V., Hemlin, S. and Lockeretz, W. (2002) 'Organic livestock production as viewed by Swedish farmers and organic initiators', Agriculture and Human Values, Vol. 19, pp.255-268.

Maurer, J. (1997) 'Umstellung auf Biolandbau in der Schweiz- motivation und Hemmnisse', in U. Köpke and J.A. Eisele (Eds). Beitrage zur 4. Wissenschaftstagung zum ökologischen Landbau, 3-4 March, Bonn. Berlin: Verlag Dr. Köster. 
McCann, E., Sullivan, S., Erickson, D. and Young, R.D. (1997) 'Environmental awareness, economic orientation, and farming practices: a comparison of organic and conventional farmers', Environmental Management, Vol. 21, pp.747-758.

Michelsen, J. (2001a) 'Organic farming in a regulatory perspective: the Danish case', Sociologia Ruralis, Vol. 41, pp.62-84.

Michelsen, J. (2001b) 'Recent development and political acceptances of organic farming in Europe', Sociologia Ruralis, Vol. 41, pp.3-19.

Michelsen, J. and Rasmussen, H. (2003) Nyomlagte danske oekologiske jordbrugere 1998. En beskrivelse basered paa en spoersgekemaundersoegelse, Esbjerg: University of Southern Denmark.

Padel, S. (2001) 'Conversion to organic farming: a typical example of the diffusion of an innovation', Sociologia Ruralis, Vol. 41, pp.49-61.

Padel, S. (2002) Conversion to Organic Milk Production: The Change Process and Farmers' Information Needs, Aberystwyth: Institute of Rural Studies, University of Wales.

Padel, S. (2005) 'D21: focus groups of value concepts of organic producers and other stakeholders', Organic Revision - Research to Support Revision of the EU Regulation on Organic Agriculture, Aberystwyth: University of Wales.

Pugliese, P. (2001) 'Il profilo dell'operatore agricolo biologico pugliese', I produttori biologici in Puglia: tipologie, problemi e prospettive, AAVV. Regione Puglia, Bari, C.I.H.E.A.M. Tecnomack.

Reed, M. (2005) "The socio-geographies of organic farming and "conventionalisation": an examination through the academic road trip', Paper presented at the XXI Congress of the ESRS, Vol. 22-27, August, Keszthely, Hungary.

Rogers, E.M. (1983) Diffusion of Innovation, New York: The Free Press.

Rogers, E.M. and Shoemaker, F.F. (1971) Communication of Innovations: A Cross-Cultural Approach, New York: Free Press.

Scaridigno, A. (2001) 'Le tipologie di produttori biologici: una metodologia di indagine'. I produttori biologici in Puglia: tipologie, problemi e prospettive, AAVV Regione Puglia, Bari, C.I.H.E.A.M. Tecnomack.

Taylor, D.L. and Miller, W.L. (1978) 'The adoption process of environmental innovations: a case study of a government project', Rural Sociology, Vol. 43, pp.634-648.

Vartdal, B. (1993) Motivatsjon og meistring av omlegging til oekologisk jordbruk, Trondheim, Sentre for bygedforskning and NORSOEK.

Willer, H. and Yussefi, M. (2005) The World of Organic Agriculture: Statistics and Emerging Trends, IFOAM-International Federation of Organic Agriculture Movements.

Willer, H. and Yussefi, M. (2006) The World of Organic Agriculture: Statistics and Emerging Trends 2006, IFOAM-International Federation of Organic Agriculture Movements.

Zanoli, R. (Ed) (2004) The European Consumer and Organic Food, Aberystwyth: School of Management and Business, University of Wales. 